\title{
Teknik 'Dais' : Satu Kaedah Pembelajaran untuk Meningkatkan Kemahiran Melakar Graf Fungsi Eksponen Dan Logaritma
}

'Dais' Technique: A Learning Method to Increase Skill in Sketching Exponential Function and Logarithm Graphs

\author{
${ }^{1}$ Aw Yang Ai Shin, ${ }^{2}$ Jenny Ku Fui Ling \\ 1,2Unit Matematik, Kolej Matrikulasi Labuan \\ 1aishinawyang@gmail.com, ${ }^{2} \mathrm{ku}$ _jenny207@yahoo.com
}

\begin{abstract}
Abstrak
Kajian ini dijalankan untuk menentukan dan mengatasi masalah melakar graf fungsi eksponen dan logaritma. Tinjauan awal dilaksanakan melalui pemerhatian hasil kerja pelajar dalam latihan/tugasan tutorial, kuiz, ujian pra dan temubual menunjukkan pelajar tidak dapat melakar graf fungsi eksponen dan logaritma dengan tepat dan lengkap. Pelajar langsung tidak tahu/faham langkah kerja yang perlu dicari sebelum melakarkan graf fungsi eksponen dan logaritma, serta keliru dengan bentuk graf fungsi tersebut. Perancangan tindakan difokuskan kepada teknik 'DAIS' untuk meningkatkan kefahaman dan kemahiran pelajar bagi melakarkan graf fungsi eksponen dan logaritma. Keputusan ujian pos telah menunjukkan peningkatan prestasi pelajar. Dapatan temubual pula menunjukkan pelajar lebih memahami dan seronok belajar melakar graf fungsi eksponen dan logaritma melalui teknik 'DAIS'.
\end{abstract}

Kata kunci Lakar graf fungsi, DAIS, teknik pembelajaran

\begin{abstract}
The aims of the study is to determine and overcome problems associated with sketching exponential function and logarithm graphs. Surveys on student works (assignment, quiz and test) and interviews showed that students were unable to sketch correctly and acurately exponential function and logarithm graphs because of the lack of understanding on the procedural works that they must undertake before sketching the graphs. A learning method called 'DAIS' was employed to help student to overcome the problems. 'DAIS' is an acronym for $\mathrm{D}=$ Domain, $\mathrm{A}=$ Asymtote, $\mathrm{I}=$ Intercepts and $\mathrm{S}=$ Sign. Post test results show that there is an increase in the performance of the student's skills after using the 'DAIS' technique.
\end{abstract}

Keywords Sketching functional graph, DAIS, learning technique

\section{PENGENALAN}

Fungsi Eksponen dan Logaritma merupakan salah satu subtopik di bahagian topik kelima di dalam subjek Matematik QS015 (Semester I) dan diperuntukkan sebanyak dua jam masa pengajaran dan pembelajaran, di mana pelajar dikehendaki melakar graf Fungsi Eksponen 
dan Logaritma. Pelajar belum didedahkan dengan Fungsi Eksponen dan Logaritma di sekolah menengah, maka, ia merupakan perkara baharu bagi mereka.

Penyelidik mengimbas kembali pelajaran Fungsi Eksponen dan Logaritma dengan menunjukkan beberapa contoh penyelesaian dalam kuliah sebelum ini.

Isi kandungan subtopik ini adalah seperti berikut:

Fungsi eksponen dan logaritma wujud dalam pelbagai bentuk, sebagai contoh

a. $f(x)= \pm e^{a x}$, where $a>0 ; f(x)= \pm e^{a x}$, where $a>0$

b. $f(x)= \pm e^{a x+b}$, where $a>0 ; f(x)= \pm e^{a x+b}$, where $a>0$

c. $f(x)= \pm e^{a x+b} \pm c$, where $a>0 ; f(x)= \pm e^{a x+b} \pm c$, where $a>0$

d. $f(x)= \pm \operatorname{In}(a x)$, where $a>0 ; f(x)= \pm \operatorname{In}(a x)$, where $a>0$

e. $f(x)= \pm \operatorname{In}(a x+b)$, where $a>0 ; f(x)= \pm \operatorname{In}(a x+b)$, where $a>0$

f. $f(x)= \pm \operatorname{In}(a x+b) \pm c$, where $a>0 ; f(x)= \pm \operatorname{In}(a x+b)$, where $a>0$

Pelajar mula buat latihan dalam buku tutorial. Didapati seramai 9 daripada 11 orang pelajar menghadapi masalah untuk melakar graf dan kurang yakin serta tidak berminat langsung untuk lakar graf fungsi eksponen dan logaritma.

Hanya dua orang pelajar sahaja yang boleh jawab soalan, malah semua pelajar rasa kurang yakin dan tidak berminat serta merasa subtopik ini amat keliru dan susah difahami. Masalah ini dapat dikesan melalui pertanyaan/respons yang diberi oleh pelajar seperti berikut:

"Apakah langkah kerja yang harus dibuat semasa melakar graf, kami amat keliru"

"Topik ini sangat susahlah, kami tidak berminat untuk lakar graf."

"Kalau tak guna cara ini, ada cara lain yang lebih mudah tak ?"

Masalah yang sama berlaku pada setiap sesi dan kelas tutorial yang berbeza. Maklum balas yang diberikan oleh pelajar dan keazaman untuk meningkatkan kefahaman dan minat pelajar terhadap subtopik ini telah mendorong penyelidik untuk menjalankan kajian. Penyelidik telah berbincang dengan Subject Matter Expert (SME) Matematik dari Kolej Matrikulasi Melaka, untuk mengkaji sebab-sebab dan cara terbaik untuk membantu pelajar dalam melakar graf fungsi eksponen dan logaritma dengan mudah dan yakin.

\section{FOKUS KAJIAN}

Penyelidik telah menganalisis soalan Ujian Pertengahan Semester (UPS) dan Peperiksaan Semester Program Matrikulasi (PSPM) tahun-tahun lepas mendapati bahawa soalan mengenai fungsi eksponen dan logaritma kerap wujud dan menyumbang antara lima ke sepuluh markah. Jika pelajar dapat menguasai subtopik ini, ia amat membantu pelajar 
bukan sahaja dalam ujian atau peperiksaan, malah, subtopik ini juga berkait rapat dengan subtopik dalam topik Kamiran (Integration) di dalam subjek Matematik QS025(Semester II), iaitu mencari luas di bawah graf fungsi eksponen dan logaritma. Masalah utama yang dihadapi oleh pelajar dalam subtopik fungsi eksponen dan logaritma ialah memahami dan mengingati langkah kerja yang perlu dilakukan sebelum melakar graf fungsi tersebut.

Penyelidik yakin jika dapat mempelbagai dan meningkatkan kaedah pengajaran dan pembelajaran(PdP) yang sedia ada dengan satu teknik PdP yang menarik, maka masalah ini akan diatasi.

Lantaran itu, teknik 'DAIS' diperkenalkan kepada pelajar sebagai satu medium pemudah cara untuk para pelajar memahami dan mengingati langkah-langkah penting yang harus dibuat semasa melakar graf eksponen dan logaritma.

\section{OBJEKTIF KAJIAN}

\section{Objektif Am}

Kajian ini bertujuan meningkatkan kemahiran pelajar untuk melakukan langkah-langkah kerja penting yang harus dilakukan sebelum melakar graf fungsi eksponen dan logaritma melalui teknik 'DAIS'.

\section{Objektif Khusus}

1. Meningkatkan kemahiran pelajar untuk mengikut langkh-langkah kerja yang penting sebelum melakar graf melalui teknik 'DAIS'

2. Meningkatkan minat pelajar melakar graf fungsi eksponen dan logaritma.

3. Mengubah cara pengajaran pensyarah supaya pelajar merasakan proses pembelajaran melakarkan graf fungsi eksponen dan logaritma adalah menyeronokkan.

\section{Kumpulan Sasaran}

Kajian ini melibatkan seramai 11 orang pelajar kumpulan tutoran CP3T35 yang terdiri daripada empat orang lelaki dan tujuh orang perempuan.

\section{Pelaksanaan Kajian}

Tinjauan Masalah

Dalam pelaksanaan kajian ini, tinjauan masalah dibuat berdasarkan pemerhatian, ujian pra dan pos, dan temubual.

\section{Pemerhatian}

Penyelidik telah membuat pemerhatian ke atas tingkah laku pelajar semasa proses pengajaran dan pembelajaran berlangsung sebelum dan selepas kajian. Sebelum kajian dijalankan pelajar kurang memberi respons kepada soalan yang diajukan malah selalu 
menunduk muka sebab tidak yakin dan juga tidak dapat menjawab soalan tutoran/latihan yang diberi dalam kelas.

\section{Ujian Pra dan Pos}

Ujian pra diberikan kepada kumpulan sasaran pada 19/8/2015 (Rabu) untuk mengesan sejauh mana kefahaman dan ingatan mereka terhadap subtopik fungsi eksponen dan logaritma. Item Ujian Pra merupakan item soalan subjektif. Selepas saya menyemak jawapan pelajar, saya tidak memulangkan kertas jawapan pelajar dan tidak membincangkan jawapannya. Sebaliknya, saya telah memperkenalkan teknik 'DAIS' kepada mereka pada keesokan harinya. Seminggu selepas itu, iaitu pada 26/8/2015, saya telah memberikan Ujian Pos dengan menggunakan set soalan yang sama bentuk dengan Ujian Pra.

\section{Temubual}

Temubual dijalankan terhadap 11 orang pelajar untuk mendapat maklumbalas tentang kesulitan yang dihadapi dan pandangan mereka tentang lakaran graf fungsi eksponen dan logaritma.

\section{ANALISIS TINJAUAN MASALAH}

\section{Analisis pemerhatian}

Berdasarkan pemerhatian selepas kajian dijalankan terhadap kumpulan sasaran didapati :

a. Pelajar lebih berkeyakinan untuk menjawab soalan yang diajukan oleh pensyarah secara lisan. Mereka menjawab dengan suara yang lantang dan tidak lagi menundukkan muka apabila pensyarah menyoal.

b. Suasana pembelajaran di dalam kelas lebih memberangsangkan dan ceria.

\section{Analisis Ujian Pra dan Pos}

Perbandingan pencapaian pelajar dalam Ujian Pra dan Pos adalah seperti di Jadual 1. Dapatan ujian pra dan pos menunjukkan terdapat peningkatan dari segi pencapaian pelajar, iaitu terdapat sembilan orang pelajar yang mendapat skor cemerlang ( $80 \%$ dan ke atas) berbanding dengan ujian pra di mana tiada seorang pun dapat skor cemerlang. Tambahan pula, tiada seorang pun pelajar mendapat skor $50 \%$ dan ke bawah pada ujian pos, tetapi terdapat seramai sembilan orang pelajar gagal mendapat skor $50 \%$ dan ke atas pada ujian pra. Analisis juga menunjukkan bahawa tiada seorang pun pelajar yang mendapat sifar pada ujian pos berbanding dengan ujian pra di mana seorang pelajar telah mendapat sifar.

\section{Analisis Temu bual}

Berdasarkan analisis ujian pra, didapati seramai sembilan daripada 11 orang pelajar telah mendapat markah rendah daripada 50\%. Satu sesi temu bual telah dijalankan ke atas sembilan orang pelajar. Di antara masalah yang telah dikenalpasti ialah; mereka keliru dan 
Jadual 1 Perbezaan Pencapaian Ujian Pra dan Ujian Pos

\begin{tabular}{ccccc}
\hline \multirow{2}{*}{ Pelajar } & \multicolumn{4}{c}{ Pencapaian } \\
\cline { 2 - 5 } & \multicolumn{3}{c}{ Ujian Pra } & \multicolumn{3}{c}{ Ujian Pos } \\
\cline { 2 - 5 } Markah/24 & Peratus & $0 \%$ & 20 & $83.3 \%$ \\
P1 & 0 & $16.7 \%$ & 21 & $87.5 \%$ \\
P3 & 4 & $20.8 \%$ & 20 & $83.3 \%$ \\
P4 & 5 & $20.8 \%$ & 24 & $100 \%$ \\
P5 & 5 & $25 \%$ & 23 & $95.8 \%$ \\
P6 & 6 & $29.2 \%$ & 17 & $70.8 \%$ \\
P7 & 7 & $37.5 \%$ & 24 & $100 \%$ \\
P8 & 9 & $37.5 \%$ & 24 & $100 \%$ \\
P9 & 9 & $41.7 \%$ & 18 & $75 \%$ \\
P10 & 10 & $54.2 \%$ & 21 & $87.5 \%$ \\
P11 & 13 & $70.8 \%$ & 24 & $100 \%$ \\
\hline
\end{tabular}

tidak boleh ingat bentuk asas graf dan tidak pasti langkah kerja yang penting yang harus dilakukan sebelum lakar graf eksponen dan logaritma.

Berikut merupakan di antara respons yang diberikan oleh sebahagian daripada sembilan pelajar sebelum menggunakan teknik 'DAIS':

"Saya langsung tak ingat bentuk asas graf fungsi eksponen dan logaritma kerana terlalu banyak bentuk sehingga saya rasa keliru."

"Saya tidak tahu cari titik-titik persilangan yang harus diberi dalam graf fungsi eksponen dan logaritma."

"Saya rasa amat keliru dalam lakaran graf fungsi eksponen dan logaritma, sehingga tak tahu apa harus saya lakukan semasa melakar graf ini."

"Saya dah banyak kali cuba, tapi masih tidak boleh ingat apa yang harus dibuat semasa melakar graf fungsi eksponen dan logaritma."

"Cara melakar graf fungsi eksponen dan logaritma sangat susah dan amat mengelirukan sehingga saya tidak berminat langsung dalam topik ini."

Selepas ujian pos, satu sesi temu bual dijalankan. Pelajar telah memberikan respons positif. Berikut merupakan hasil temu bual dengan sebahagian daripada sembilan orang pelajar:

"Saya lebih yakin kerana prosesnya mudah."

"Semua proses menggunakan pengetahuan sedia ada yang memang saya ingat."

"Walaupun saya bermasalah dalam melakar graf fungsi eksponen dan logaritma, tetapi teknik ini dapat membantu menyelesaikan masalah saya."

“ Teknik ini menyebabkan saya lebih yakin graf yang saya lakar adalah betul.”

"Saya sukakan teknik ini kerana saya berasa yakin lakaran graf saya betul." 
"Apabila menggunakan teknik ini, saya tidak ragu-ragu untuk lakukan langkah kerja yang perlu semasa melakar graf fungsi eksponen dan logaritma, dan seterusnya dapat melakar graf dengan tepat dan lengkap."

Hasil daripada temubual menunjukkan bahawa setelah mempelajari teknik ini, ianya dapat membantu pelajar mengingati langkah-langkah kerja yang perlu dibuat semasa melakar graf fungsi eksponen dan logaritma dan seterusnya meningkatkan kemahiran melakar graf fungsi berkenaan. Teknik ini juga dapat meningkatkan keyakinan pelajar bahawa jawapan yang mereka perolehi adalah betul dan tepat.

\section{TINDAKAN YANG DIJALANKAN}

Setelah melakukan tinjauan awal melalui Ujian Pra, pemerhatian dalam kelas dan temu bual, fokus diberikan kepada memperkenalkan tips atau strategi pengajaran dan pembelajaran iaitu teknik 'DAIS' untuk melakar graf fungsi eksponen dan logaritma dengan lengkap dan tepat.

Contoh penggunaan teknik 'DAIS' dalam lakaran graf fungsi eksponen dan logaritma adalah seperti berikut:

Soalan :
1. (a) $f(x)=e^{x}-2$
(b) $f(x)=3-e^{-x}$
2. (a) $f(x)=\operatorname{In}(1-x)$
(b) $f(x)=2-\operatorname{In}(x-3)$

Penyelesaian :

1. (a) $f(x)=e^{x}-2$

* guna 'DAIS' untuk mencari langkah kerja yang penting sebelum lakar graf, iaitu

$\mathrm{D}=$ Domain , $\mathrm{A}=$ Asymptote , $\mathrm{I}=$ Intercepts , $\mathrm{S}=$ Sign

i. $\quad \mathrm{D}:(-\infty, \infty)$

ii. $\mathrm{A}: y=-2$

iii. I: when $x=0, f(0)=e^{0}-2$

(a) $f(x)=e^{x}-2$

Asymptote

$$
=1-2
$$$$
=-1
$$

iv. S :

\begin{tabular}{|c|c|}
\hline$x$ & $y$ \\
\hline$+\mathrm{ve}$ & $+\mathrm{ve}$ \\
\hline
\end{tabular}

Cari $y$-intercept

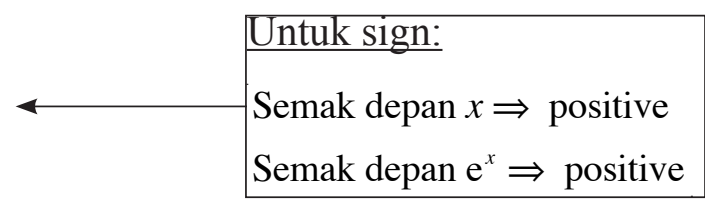




\section{Lakaran graf:}

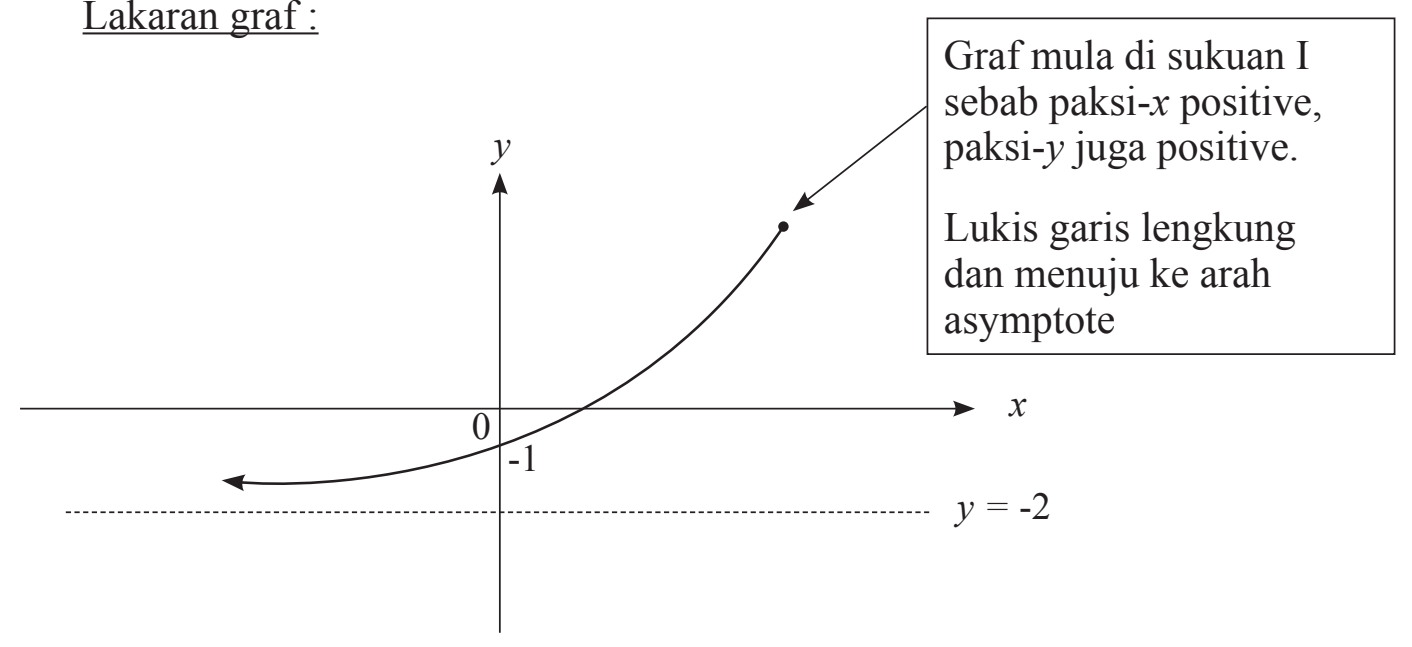

1. (b) $f(x)=3-e^{-x}=-e^{-x}+3$

iii. D : $(-\infty, \infty)$

iv. A : $y=3$

V. I : when $x=0, f(0)=3-e^{0}=2$

vi. S :

\begin{tabular}{|c|c|}
\hline$x$ & $y$ \\
\hline$-\mathrm{ve}$ & $-\mathrm{ve}$ \\
\hline
\end{tabular}

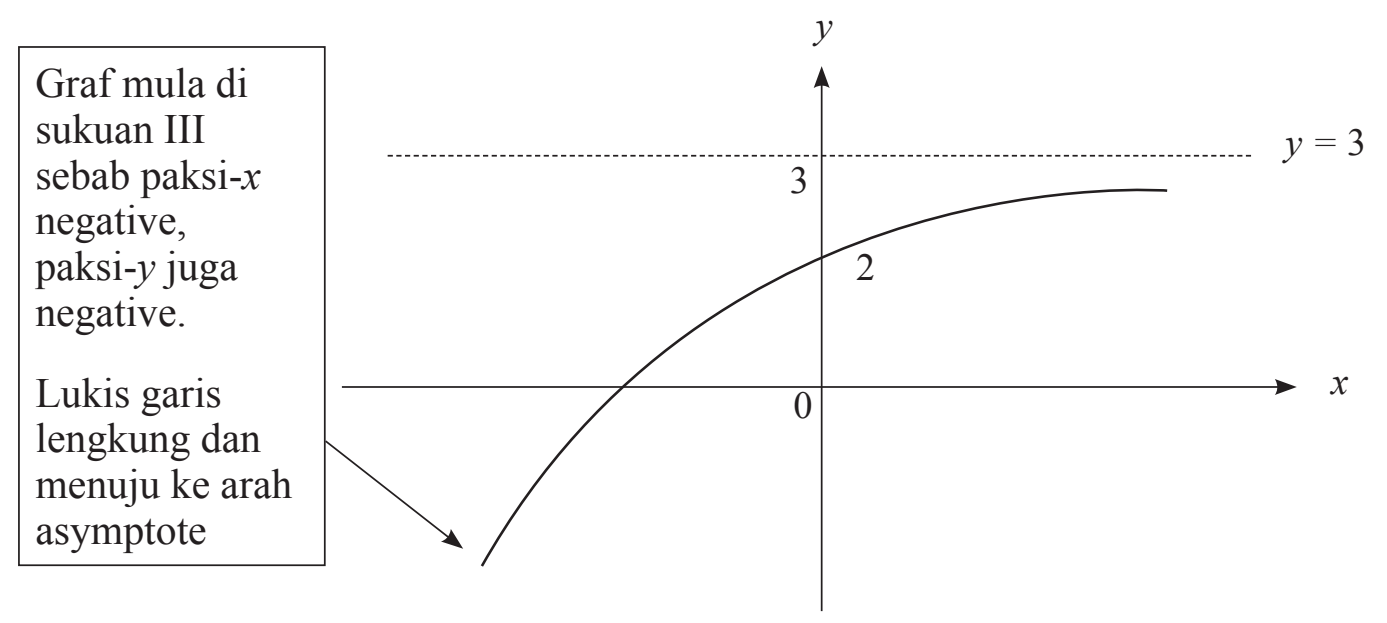

2. (a) $f(x)=\operatorname{In}(1-x)$

* guna 'DAIS' untuk mencari langkah kerja yang penting sebelum lakar graf, iaitu $\mathrm{D}=$ Domain , $\mathrm{A}=$ Asymptote, $\mathrm{I}=$ Intercepts, $\mathrm{S}=$ Sign 
i. D : $1-x>0$

$x<1$

ii. A : $x=1$

iii. I : when $f(x)=0,0=\operatorname{In}(1-x)$

Cari $x$-intercept

$$
\begin{aligned}
& e^{0}=1-x \\
& x=1-1=0
\end{aligned}
$$

iv. $\mathrm{S}$ :
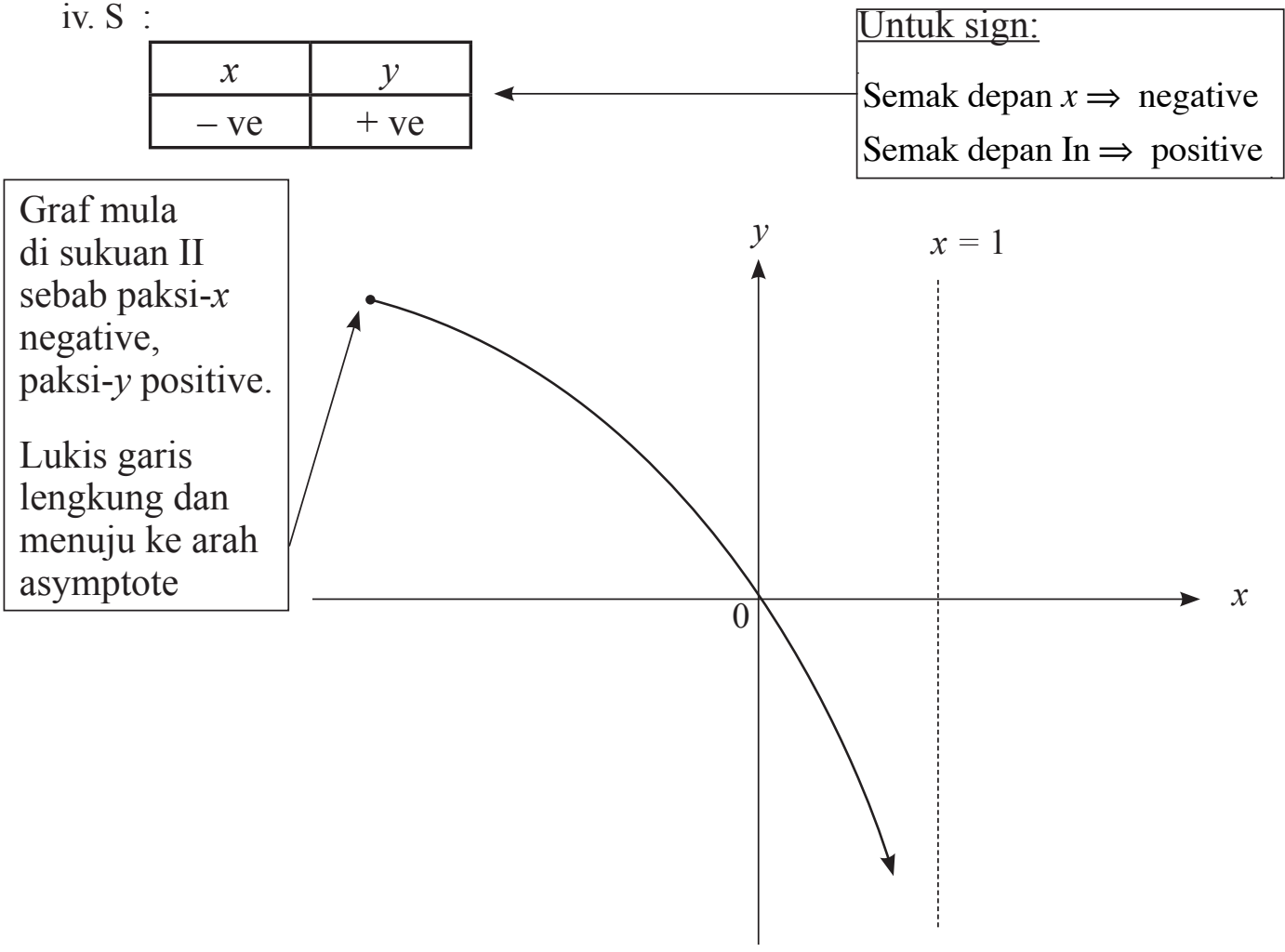

2 (b) $f(x)=2-\operatorname{In}(x-3)$

i. D : $x-3>0$

$$
x>3
$$

ii. A : $x=3$

iii. I : when $f(x)=0,0=2-\operatorname{In}(x-3)$

$$
\begin{aligned}
& \operatorname{In}(x-3)=2 \\
& x-3=e^{2} \\
& x=e^{2}+3
\end{aligned}
$$

iv. $\mathrm{S}$ :

\begin{tabular}{|c|c|}
\hline$x$ & $y$ \\
\hline$+\mathrm{ve}$ & $-\mathrm{ve}$ \\
\hline
\end{tabular}




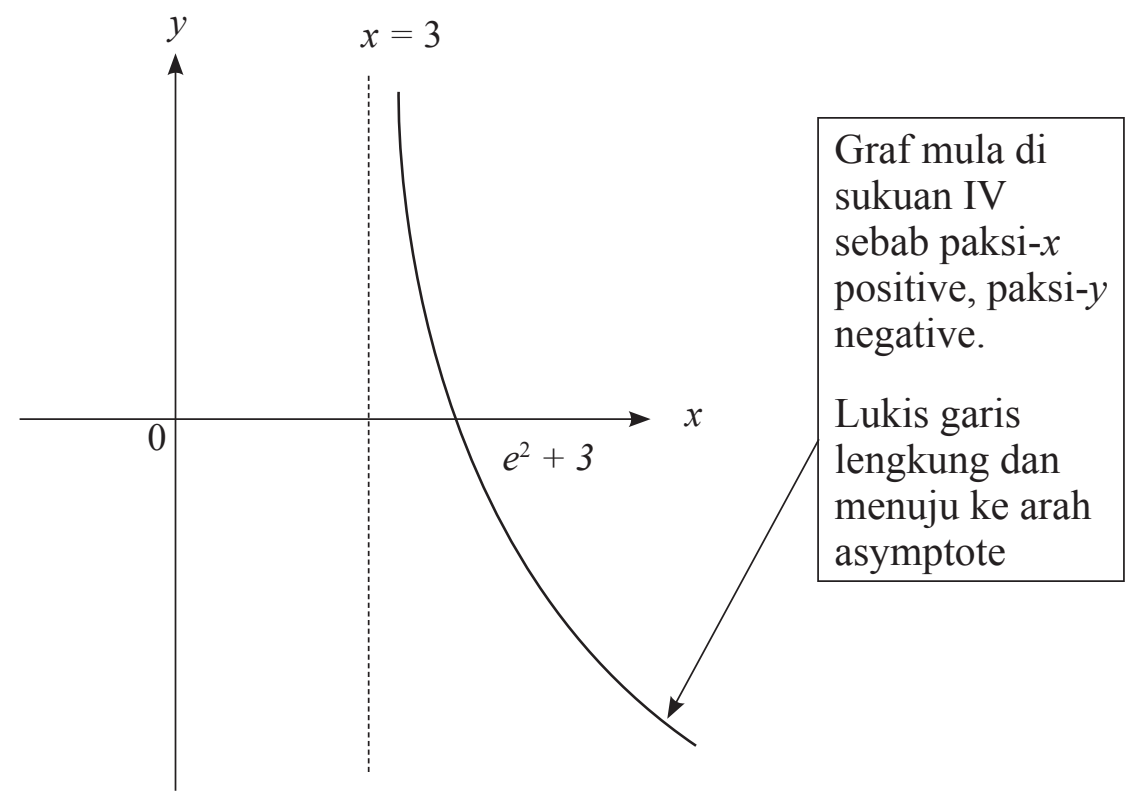

Setelah pelajar faham dan dapat menggunakan kaedah 'DAIS' iaitu satu teknik menjawab soalan dengan cara yang inovasi dan kreatif (TICK - Teknik Ingat Cara Kerja), maka pelajar tidak akan keliru lagi tentang apa langkah kerja yang harus dilakukan sebelum melakar graf fungsi eksponen dan logaritma. Seterusnya, dengan penuh yakin dan mudahnya, pelajar dapat lakar graf tersebut dengan lengkap dan tepat.

\section{PELAKSANAAN TINDAKAN DAN PEMERHATIAN / PENILAIAN}

Kajian ini telah dilaksanakan dalam tempoh dua minggu. Penyelidik telah memperuntukkan 60 minit tutorial untuk memperkenalkan teknik 'DAIS' dan menunjukkan beberapa contoh kepada mereka. Penyelidik juga membimbing mereka menjawab soalan dalam kelas. Pelajar telah menjalani ujian pos selepas enam hari belajar teknik 'DAIS'. Selepas ujian pos, satu sesi temu bual juga dijalankan. Beberapa orang pelajar telah ditemu bual dan mereka memberi respons yang positif terhadap teknik 'DAIS' ini.

Berdasarkan pemerhatian penyelidik, teknik 'DAIS' berjaya membantu pelajar meningkatkan pencapaian di dalam melakarkan graf fungsi eksponen dan logaritma. Pelajar juga lebih berkeyakinan dan seronok belajar subtopik ini dan seterusnya mendapat skor yang baik semasa menjawab ujian pos.

\section{REFLEKSI KAJIAN}

Pencapaian pelajar dalam ujian pra dan ujian pos menunjukkan peningkatan yang agak ketara. Hasil dapatan kajian juga menunjukkan bahawa teknik 'DAIS' banyak membantu pelajar meningkatkan keyakinan diri, daya ingatan dan kefahaman terhadap apa yang dipelajari di samping menjadikan suasana PdP lebih ceria dan menyeronokkan.

Masih terdapat dua orang pelajar di bawah skor $80 \%$ dalam ujian pos kerana mereka 
adalah dari kategori yang lebih lemah. Penyelidik akan membimbing mereka ini pada masa konsultasi sehingga mereka menguasai subtopik ini.

Saya berasa tersentuh dan terharu apabila dua orang pelajar yang lemah itu meminta penyelidik mengajar mereka sekali lagi kerana mereka berasa lebih faham dan yakin dengan teknik 'DAIS' tersebut.

\section{CADANGAN UNTUK KAJIAN SETERUSNYA}

Beberapa cadangan untuk kajian seterusnya adalah seperti berikut:

- Mengguna pakai teknik 'DAIS' apabila pensyarah mengajar subtopik fungsi eksponen dan logaritma.

- Pensyarah boleh menyediakan satu modul penggunaan teknik 'DAIS' dalam PdP secara lebih terancang atau teratur.

Hasil dari penyelidikan yang dijalankan, penyelidik dapati terdapat perubahan yang positif dari segi amalan pembelajaran pelajar. Semoga hasil kajian penyelidik ini dapat dimanfaatkan dan mempelajari melakarkan graf fungsi eksponen dan logaritma dalam suasana yang menarik, berkesan dan menyeronokkan.

\section{RUJUKAN}

Cheng Siak Peng, Ch'ng Pei Eng, Ch'ng Pei Cheng, Teoh Sian Hoon and Goh Chok Huat (2010).

Matriculation Mathematics, Updated Second Edition. Oriental Academic Publication, Malaysia. Manual Kajian Tindakan, EPRD, KPM 2004.

Mathematics Syllabus Specification QS015. Matriculation Division. Ministry of Education Malaysia. Ong Beng Sim, Lee Khaik Yong, Siti Eishah Bt Ishak, Fauzi Mohamed Yusof and Raja Suzita Bt Raja Suleiman. Mathematics for Matrculation Semester 1, Second Edition Updated. Oxford Fajar Sdn. Bhd. 